Article

\title{
An Improvement in Diagnostic Blood Culture Conditions Allows for the Rapid Detection and Isolation of the Slow Growing Pathogen Yersinia pestis
}

\author{
Efi Makdasi *, ${ }^{\text {, }}$ Yafit Atiya-Nasagi ${ }^{\dagger}$, David Gur, Ayelet Zauberman (D, Ofir Schuster (D, Itai Glinert, \\ Shlomo Shmaya, Elad Milrot, Haim Levy (D), Shay Weiss, Theodor Chitlaru, Emanuelle Mamroud (D) \\ and Orly Laskar*D
}

Citation: Makdasi, E.; Atiya-Nasagi, Y.; Gur, D.; Zauberman, A.; Schuster, O.; Glinert, I.; Shmaya, S.; Milrot, E.; Levy, H.; Weiss, S.; et al. An Improvement in Diagnostic Blood Culture Conditions Allows for the Rapid Detection and Isolation of the Slow Growing Pathogen Yersinia pestis. Pathogens 2022, 11, 255. https://doi.org/10.3390/ pathogens11020255

Academic Editor: Florian Liegeois

Received: 26 January 2022

Accepted: 14 February 2022

Published: 16 February 2022

Publisher's Note: MDPI stays neutral with regard to jurisdictional claims in published maps and institutional affiliations.

Copyright: (C) 2022 by the authors. Licensee MDPI, Basel, Switzerland. This article is an open access article distributed under the terms and conditions of the Creative Commons Attribution (CC BY) license (https:// creativecommons.org/licenses/by/ $4.0 /)$.
Israel Institute for Biological Research, Ness-Ziona 74100, Israel; yafita@iibr.gov.il (Y.A.-N.); gurd@iibr.gov.il (D.G.); ayeletz@iibr.gov.il (A.Z.); ofirsc@iibr.gov.il (O.S.); itaig@iibr.gov.il (I.G.); shlomosh@iibr.gov.il (S.S.); eladm@iibr.gov.il (E.M.); haiml@iibr.gov.il (H.L.); shayw@iibr.gov.il (S.W.); theodorc@iibr.gov.il (T.C.); emmym@iibr.gov.il (E.M.)

* Correspondence: efim@iibr.gov.il (E.M.); orlyl@iibr.gov.il (O.L.); Tel.: +972-8-9381667 (E.M. \& O.L.)

+ These authors contributed equally to this work.

\begin{abstract}
Plague, caused by the human pathogen Yersinia pestis, is a severe and rapidly progressing lethal disease that has caused millions of deaths globally throughout human history and still presents a significant public health concern, mainly in developing countries. Owing to the possibility of its malicious use as a bio-threat agent, $Y$. pestis is classified as a tier- 1 select agent. The prompt administration of an effective antimicrobial therapy, essential for a favorable patient prognosis, requires early pathogen detection, identification and isolation. Although the disease rapidly progresses and the pathogen replicates at high rates within the host, Y. pestis exhibits a slow growth in vitro under routinely employed clinical culturing conditions, complicating the diagnosis and isolation. In the current study, the in vitro bacterial growth in blood cultures was accelerated by the addition of nutritional supplements. We report the ability of calcium $\left(\mathrm{Ca}^{+2}\right)$ - and iron $\left(\mathrm{Fe}^{+2}\right)$-enriched aerobic blood culture media to expedite the growth of various virulent $Y$. pestis strains. Using a supplemented blood culture, a shortening of the doubling time from $\sim 110 \mathrm{~min}$ to $\sim 45 \mathrm{~min}$ could be achieved, resulting in increase of 5 order of magnitude in the bacterial loads within $24 \mathrm{~h}$ of incubation, consequently allowing the rapid detection and isolation of the slow growing Y. pestis bacteria. In addition, the aerobic and anaerobic blood culture bottles used in clinical set-up were compared for a Y. pestis culture in the presence of $\mathrm{Ca}^{+2}$ and $\mathrm{Fe}^{+2}$. The comparison established the superiority of the supplemented aerobic cultures for an early detection and achieved a significant increase in the yields of the pathogen. In line with the accelerated bacterial growth rates, the specific diagnostic markers F1 and LcrV (V) antigens could be directly detected significantly earlier. Downstream identification employing MALDI-TOF and immunofluorescence assays were performed directly from the inoculated supplemented blood culture, resulting in an increased sensitivity and without any detectable compromise of the accuracy of the antibiotic susceptibility testing (E-test), critical for subsequent successful therapeutic interventions.
\end{abstract}

Keywords: Y. pestis; plague; blood culture; F1 and V antigens; bacterial diagnostics

\section{Introduction}

Plague, one of the oldest recorded human pestilences, is a severe and rapidly progressing lethal infectious disease that has caused millions of deaths throughout human history. The disease is still present in different parts of the world with the last 20 years witnessing a global rise in plague incidence. Recent outbreaks have been reported in Uganda [1], China [2], The Democratic Republic of Congo [3] and Madagascar [4].

$Y$. pestis, the causative agent of plague, is a Gram-negative bacterium, circulating among rodents and most commonly spread to humans via fleas. A delayed treatment 
results in high mortality rates [5]. Hence, the prompt identification of the pathogen is crucial for a proper and timely treatment.

According to the World Health Organization (WHO) indications, plague is diagnosed by the positive isolation and identification of $Y$. pestis in a culture or in retrospect by a seroconversion specific for the capsular F1 antigen.

Although the clinical course of the infection is characterized by a fast progression in vivo, all known $Y$. pestis strains exhibit slow a growth in vitro. A clinical diagnosis may require 24-72 $\mathrm{h}$ incubation to enable the colony isolation followed by an additional $24-48 \mathrm{~h}$ required for an accurate antibiotic susceptibility determination. The early administration of an effective antimicrobial therapy is essential for favorable patient outcomes; thus, the early detection and isolation of the pathogen is instrumental for an effective treatment. As bacteremia is common in bubonic, pneumonic and septicemic plague, clinical blood samples are relevant specimens for the isolation and diagnosis of $Y$. pestis. Specifically, blood cultures are considered to be the gold standard of sepsis diagnostics.

In clinical set-ups, peripheral blood sampling combined with automated alert culture systems are routinely implemented owing to their simplicity and high sensitivity. Yet, in more than $50 \%$ of patients, the bacteremia is less than 1 colony-forming unit (CFU)/mL [6]; therefore, a significant volume of blood sampling is necessary for detection (usually $10 \mathrm{~mL}$ per bottle in 2 to 3 sets of aerobic and anaerobic blood cultures). Taken together, the slow growth rate of $Y$. pestis and a low initial CFU count per sample potentially result in prolonged incubation times prior to a positive identification.

The importance of an early diagnosis has incented the development of culturing methods that exhibit an improved efficiency and selectivity for colony isolation [7-9] as well as rapid and sensitive approaches for the detection of $Y$. pestis directly from clinical samples. These are mainly based on immune-labeling [10,11], reporter phage [12-14] and genetic assays [15]. Usually, the selective media act by imposing a limitation of specific nutrients and/or the inclusion of selective antimicrobials, thus promoting the preferential growth of a particular targeted microorganism. Although effective in discerning amongst microorganisms, the restrictions imposed by the selective media tend to retard growth, often resulting in a delayed colony formation [7].

It is well-established that metal ions are essential elements in bacterial metabolism and growth. Specifically, iron $\left(\mathrm{Fe}^{+2}\right)$ ions serve as a metabolic cofactor necessary for crucial processes including respiration, oxidative stress resistance and virulence factor production [16]. Generally, the level of iron required for an optimal bacterial growth is $\sim 10^{-6} \mathrm{M}$; however, the level of free iron in mammalian tissues is typically $\sim 10^{-18} \mathrm{M}$ [17]. During an infection, the host immune response includes a further limitation of iron availability from the invading pathogens by a process termed nutritional immunity [18,19]. Enriching the iron availability in a culture by an active administration or by using hemolyzed human erythrocytes was reported to increase $Y$. pestis virulence [20-22]. Another nutrient demonstrated to be crucial for $Y$. pestis growth at $37^{\circ} \mathrm{C}$ is calcium $\left(\mathrm{Ca}^{+2}\right)$. Under low calcium conditions, the bacteria undergo a specific metabolic arrest termed a low calcium response (LCR), which is characterized by restricting the vegetative growth and accompanied by the expression of the Type III secretion system and the V antigen [23,24]. Adding bloodequivalent levels of $\mathrm{Ca}^{+2}(2.5 \mathrm{mM})$ results in a reversion of the response [25-27]. In spite of the effect of $\mathrm{Fe}^{+2}$ and $\mathrm{Ca}^{+2}$ ions on bacterial growth, their addition for expediting the culture time for diagnostic purposes was not reported.

In this study, we evaluated the bacterial growth rates of virulent $Y$. pestis strains in $\mathrm{Fe}^{+2}$ - and $\mathrm{Ca}^{+2}$-enriched blood cultures as a means for improving and accelerating bacterial growth. The shortening of the culturing time facilitated a rapid pathogen detection and isolation, positively impacting on the clinical diagnosis and enabling the prompt onset of an efficient therapy. 


\section{Results and Discussion}

\subsection{Accelerated Growth Rates of Y. pestis in Iron- and Calcium-Supplemented Blood Cultures}

In order to evaluate the bacterial growth rates of virulent $Y$. pestis strains in $\mathrm{Fe}^{+2}$ - and $\mathrm{Ca}^{+2}$-enriched blood cultures, the Kimberley53 (Kim53, biovar Orientalis, Table 1) strain was spiked into BACTEC Plus Aerobic/F culture vials containing $10 \mathrm{~mL}$ of naïve fresh human blood. Initially, we assessed the impact of adding $\mathrm{Fe}^{+2}(100 \mu \mathrm{M})$ and $\mathrm{Ca}^{+2}(2.5 \mathrm{mM})$ separately or in a combination compared with a non-supplemented blood culture. The vials were incubated at $150 \mathrm{rpm}$ at $37^{\circ} \mathrm{C}$ for $24 \mathrm{~h}$ and the bacterial growth was determined during and following the incubation by colony-forming unit (CFU) counts. As shown in Figure 1, the blood cultures supplemented with $\mathrm{Fe}^{+2}$ and $\mathrm{Ca}^{+2}$ separately allowed increased $Y$. pestis growth rates compared with the non-supplemented media. Twenty-four hours after the initiation of the culture, the improved growth rate resulted in an increase of one order of magnitude in the bacterial counts. In addition, combining both supplements resulted in increase of 2order of magnitude in the bacterial counts following a $24 \mathrm{~h}$ incubation, suggesting an additive effect of the supplements. The bacterial doubling time showed a significant reduction from $\sim 110 \mathrm{~min}$ in the non-supplemented blood culture to $\sim 45 \mathrm{~min}$ in the combined $\mathrm{Fe}^{+2}$ - and $\mathrm{Ca}^{+2}$-supplemented media. These results strengthened the conclusion that the co-administration of $\mathrm{Ca}^{+2}$ and $\mathrm{Fe}^{+2}$ to the blood culture vials was highly beneficial, potentially shortening the detection times for $Y$. pestis in a clinical setting.

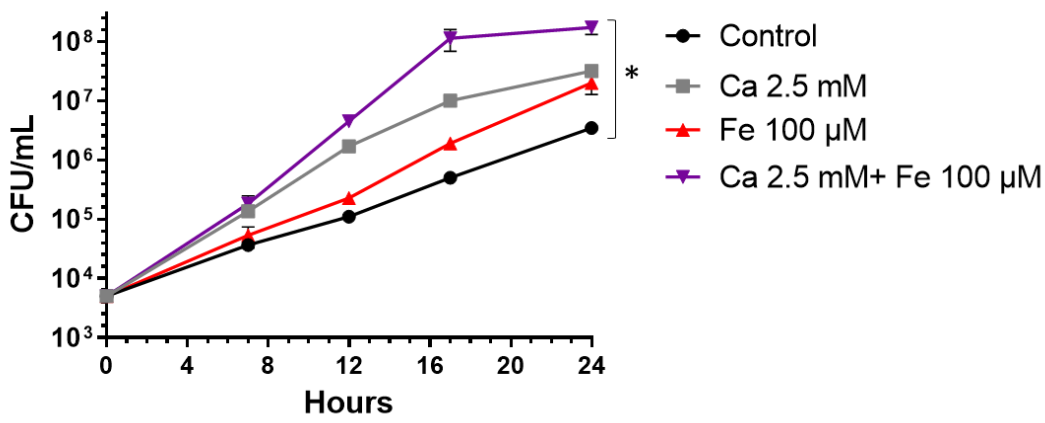

Figure 1. The effect of iron and calcium supplementation on Y. pestis growth rates. BACTEC Plus Aerobic/F culture vials containing $10 \mathrm{~mL}$ of naïve fresh human blood were spiked with the virulent $Y$. pestis Kimberley53 (Kim53) strain at a final concentration of $5 \times 10^{3} \mathrm{CFU} / \mathrm{mL}$. Fe ${ }^{+2}(100 \mu \mathrm{M})$ and Ca ${ }^{+2}$ $(2.5 \mathrm{mM})$, separately or in combination, were added to vials and then incubated at $37^{\circ} \mathrm{C}$. Bacterial growth was determined 7, 12, 17 and $24 \mathrm{~h}$ following incubation by CFU counts. Non-supplemented blood cultures were used as controls. Results are averages \pm SEM of four blood cultures for each group containing two individual blood donations and representing two independent experiments obtaining similar results. ${ }^{*} p<0.01$ of $\mathrm{Fe}^{+2}$ - and $\mathrm{Ca}^{+2}$-supplemented culture vs. non-supplemented control according to a two-tailed Student's $t$-test.

The effect of $\mathrm{Fe}^{+2}$ and $\mathrm{Ca}^{+2}$ on the bacterial growth was further demonstrated in three additional Y. pestis strains, Alexander, IV 75195 (biovar Orientalis, Table 1) and PKH-10 (biovar Medievalis, Table 1). As depicted in Figure 2, a significant increase in the bacterial counts was achieved in the supplemented samples (an increase of up to five orders of magnitude for all strains after an incubation of $24 \mathrm{~h}$ ). It is important to note that in all tested strains, the bacterial counts in the supplemented media after $12 \mathrm{~h}$ growth were equivalent to or higher than those with a non-supplemented growth $24 \mathrm{~h}$ after inoculation. This finding, along with the shortening of the doubling time (Figure 1), could potentially shorten the duration of the positive growth signal in clinical samples, accelerating the identification of pathogens by downstream processing methods such as MALDI-TOF and immunoassays as well as isolation and culturing for phenotype characterization purposes such as antibiotic sensitivity tests. 

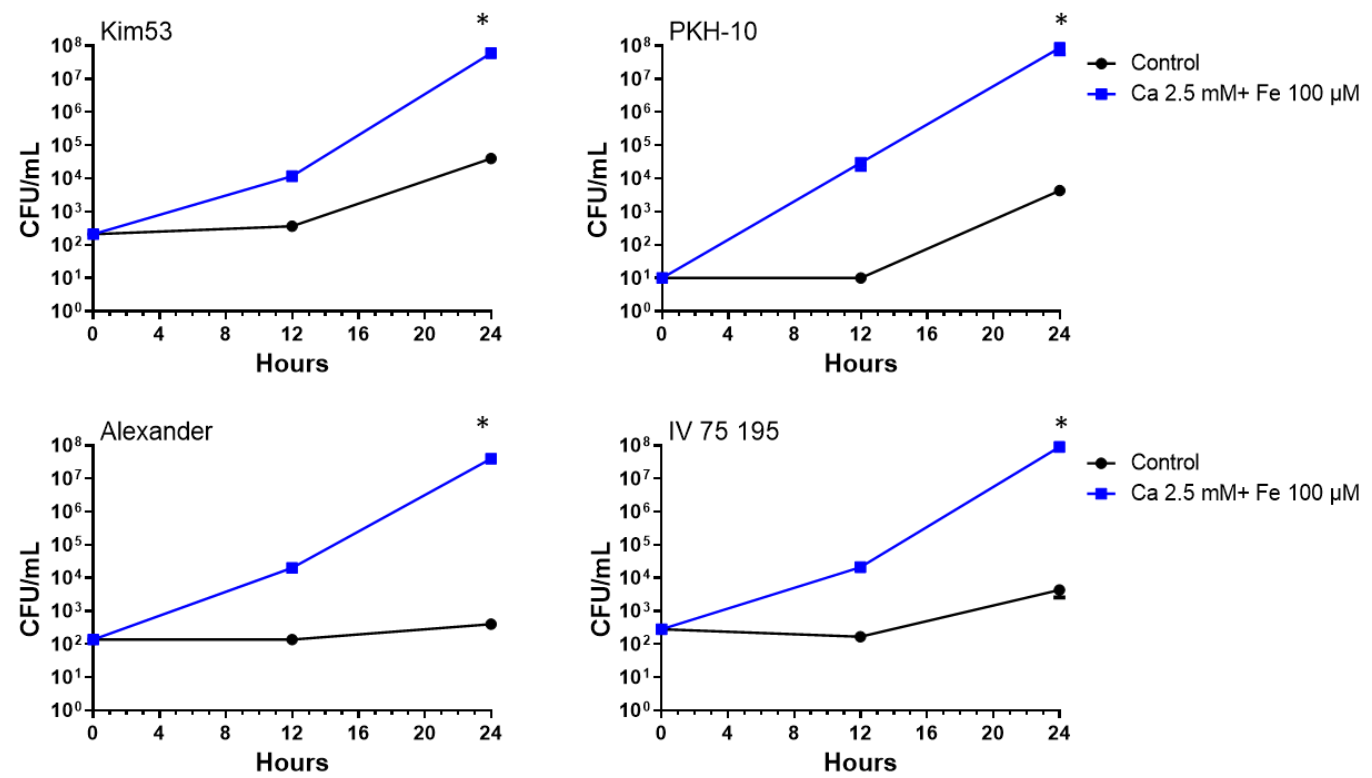

Figure 2. Accelerated growth rate of $Y$. pestis virulent strains in supplemented blood culture. BACTEC Plus Aerobic/F culture vials containing $10 \mathrm{~mL}$ of naive fresh human blood were spiked with four different virulent $Y$. pestis strains (Kim53, PKH-10, Alexander and IV 75 195) at a final concentration of $10-500 \mathrm{CFU} / \mathrm{mL}$. Vials were supplemented with $\mathrm{Fe}^{+2}(100 \mu \mathrm{M})$ and $\mathrm{Ca}^{+2}(2.5 \mathrm{mM})$ and then incubated at $37^{\circ} \mathrm{C}$. Non-supplemented blood cultures were used as a control. Bacterial growth was determined following $12 \mathrm{~h}$ and $24 \mathrm{~h}$ incubation by CFU counts. Results are averages \pm SEM of three counts each from two blood cultures per group. ${ }^{*} p<0.01$ of supplemented vs. non-supplemented control culture according to a two-tailed Student's $t$-test.

Available $\mathrm{Ca}^{+2}$ and $\mathrm{Fe}^{+2}$ in blood cultures mainly originate from the components added by the manufacturer and the peripheral blood sample itself used for the inoculation of the vial in the course of clinical sampling. Although the effective concentration of $\mathrm{Ca}^{+2}(2.5 \mathrm{mM})$ required for an optimal Y. pestis growth was previously accurately determined [25-27], information regarding the $\mathrm{Fe}^{+2}$ levels enabling Y. pestis growth in blood cultures is limited. The low stability of iron together with concerns pertaining to the potential toxicity of high iron levels motivated the determination of the optimal concentration of iron in blood cultures for $Y$. pestis growth. $\mathrm{Fe}^{+2}(10-1000 \mu \mathrm{M})$ was administered together with a constant concentration of $\mathrm{Ca}^{+2}(2.5 \mathrm{mM})$ to aerobic blood culture vials and inoculated with either virulent $Y$. pestis Kim53 or PKH-10. The vials were incubated at $150 \mathrm{rpm}$ at $37^{\circ} \mathrm{C}$ for $24 \mathrm{~h}$ and the bacterial growth was determined during and following incubation by $\mathrm{CFU}$ counts. As shown in Figure 3, the growth rates of both strains were affected by the supplemented media, achieving an increase of three and four orders of magnitude in the Kim53 and PKH-10 counts, respectively. No significant differences in the bacterial counts were observed across the range of increased $\mathrm{Fe}^{+2}$ concentrations $(10-1000 \mu \mathrm{M})$, indicating that $10 \mu \mathrm{M}$ was a sufficient concentration for bacterial growth. The calculations of the bacterial doubling times under the supplemented conditions established a doubling time of $\sim 45 \mathrm{~min}$ for both virulent strains compared with $\sim 110 \mathrm{~min}$ (Kim53) and $120 \mathrm{~min}$ (PKH-10) obtained in the non-supplemented media, substantiating the initial results. In spite of the observation that $10 \mu \mathrm{M} \mathrm{Fe}^{+2}$ was sufficient, considering the possible low stability on one hand and the potential toxicity of $\mathrm{Fe}^{+2}$ at high concentrations on the other hand, an $\mathrm{Fe}^{+2}$ concentration of $100 \mu \mathrm{M}$ was employed in all subsequent experiments.

As diagnostic blood cultures are often carried out by the inoculation of BACTEC Standard Aerobic/F culture vials (already containing hemin as a component added by the manufacturer; see Supplementary Table S1) we determined whether the increase in the growth rate was manifested in these cultures as observed in the supplemented BACTEC Plus Aerobic/F cultures. To address this issue, Kim53 and PKH-10 strains were spiked into supplemented and non-supplemented BACTEC Standard Aerobic vials containing $10 \mathrm{~mL}$ 
of fresh blood and the bacterial growth was determined after $24 \mathrm{~h}$ as previously described. BACTEC Plus Aerobic/F culture vials were used as the positive control. As shown in Figure 4, a significant increase in the bacterial counts was observed in the supplemented BACTEC Standard Aerobic culture vials, similar to the bacterial growth quantified in the BACTEC Plus Aerobic/F vials. Moreover, no differences in the bacterial growth were observed in the non-supplemented vials irrespective of the components added by the manufacturer. Overall, these results stressed that the beneficial effect of supplemented $\mathrm{Fe}^{+2}$ and $\mathrm{Ca}^{+2}$ for increasing $Y$. pestis growth rates under aerobic conditions was manifested regardless of the BACTEC vial type used.
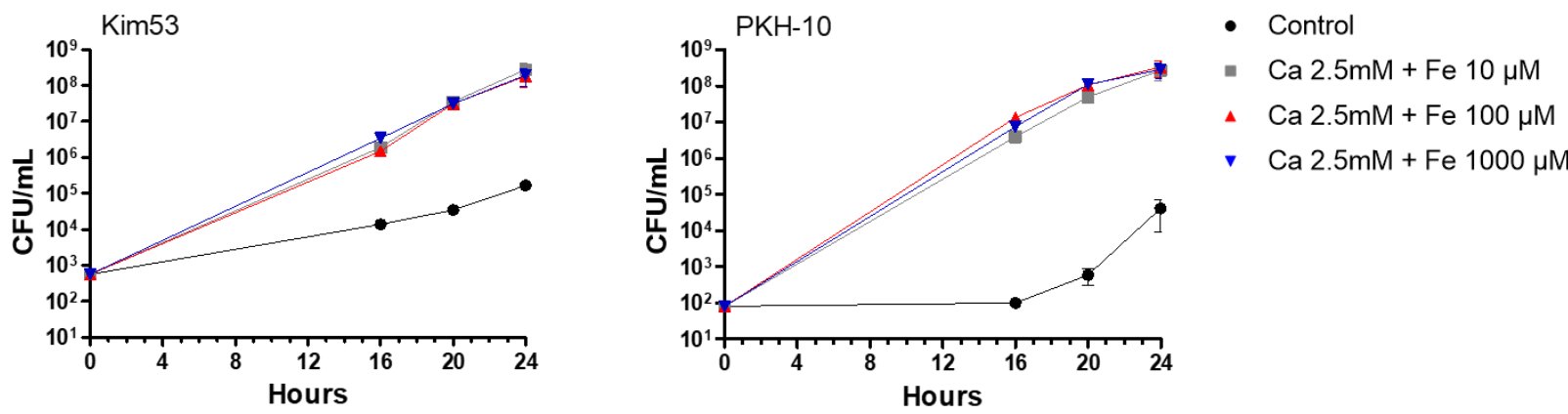

Figure 3. Optimization of iron concentrations for enhancing bacterial growth. BACTEC Plus Aerobic/F culture vials containing $10 \mathrm{~mL}$ of naive fresh human blood were spiked with Kim53 (500 CFU/mL) and PKH-10 (100 CFU/mL). Vials were supplemented with $\mathrm{Ca}^{+2}(2.5 \mathrm{mM})$ combined with three different concentrations of $\mathrm{Fe}^{+2}(10,100$ and $1000 \mu \mathrm{M})$. Non-supplemented blood cultures were used as a control. Vials were incubated at $37^{\circ} \mathrm{C}$ and bacterial growth was determined following 16,20 and $24 \mathrm{~h}$ incubation by CFU counts. Results are averages \pm SEM of three counts each of duplicate blood cultures containing two individual blood donations in each group.
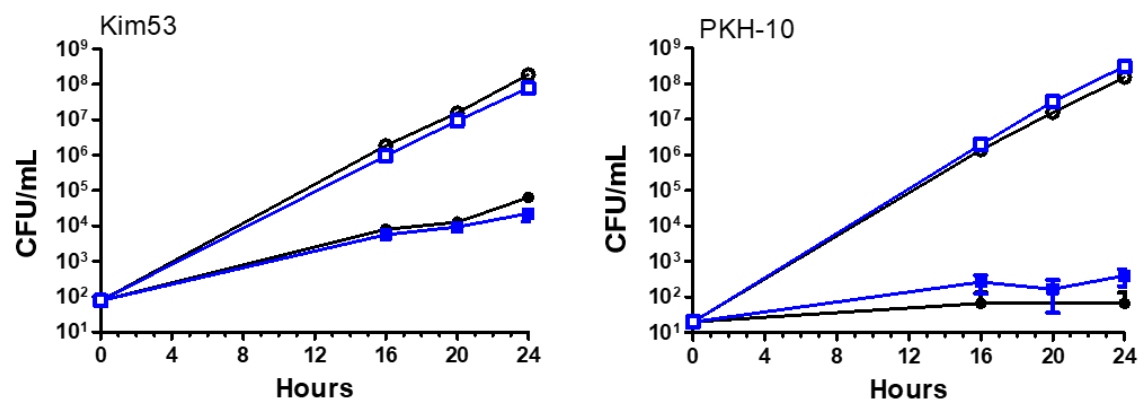

- Aerobic Plus

- Aerobic Plus + Ca \& Fe

- Standard Aerobic

- Standard Aerobic+ $\mathrm{Ca} \& \mathrm{Fe}$

Figure 4. Enhanced bacterial growth in supplemented blood cultures is maintained in BACTEC Standard Aerobic vials. BACTEC Standard Aerobic/F and BACTEC Plus Aerobic/F vials containing $10 \mathrm{~mL}$ of naive fresh human blood were spiked with Kim53 (100 CFU/mL) and PKH-10 (10 CFU/mL). Vials were supplemented with $2.5 \mathrm{mM} \mathrm{Ca}^{+2}$ and $100 \mu \mathrm{M} \mathrm{Fe}^{+2}$. Non-supplemented blood cultures were used as a control. Vials were incubated at $37^{\circ} \mathrm{C}$ and bacterial growth was determined following 16, 20 and $24 \mathrm{~h}$ incubation by CFU counts. Results are averages \pm SEM of three counts each of duplicate blood cultures containing two individual blood donations in each group.

\subsection{Y. pestis Growth in Aerobic and Anaerobic Blood Culture Vials}

The current recommendations for blood culture sampling for adult patients consist of collecting at least two pairs of vials with each set requiring $20 \mathrm{~mL}$ of blood from two distinct sampling sites distributed equally between an aerobic and anaerobic vial [28,29]. Lately, the relevance of this routine has been challenged, mostly due to the fact that the yield of anaerobic bacteria is frequently limited in these vials and is not restricted to the isolation of strictly anaerobic microorganisms [30,31]. As the incidence of anaerobic bacteremia is low, anaerobic blood cultures tend to be selectively used in patients at risk of anaerobic infections. 
In spite of the preferential clinical use of aerobic conditions, anaerobic blood culture protocols-which allow the growth of facultative organisms-may exhibit a superior sensitivity. As $Y$. pestis is classified as an anaerobic facultative bacterium, its growth in anaerobic vs. aerobic blood cultures was evaluated. Kim53 and PKH-10 bacteria were spiked into four different non-supplemented BACTEC blood cultures of two aerobic and two anaerobic vials. The vials were incubated at $150 \mathrm{rpm}$ at $37^{\circ} \mathrm{C}$ for $24 \mathrm{~h}$ and the bacterial growth was determined by the CFU counts in the course as well as following the incubation. The growth of the virulent Kim53 and PKH-10 strains was accelerated in the anaerobic vials. This was observed for the two strains both in standard and lytic anaerobic vials (Figure 5A,B). These results were in line with those reported for the attenuated $Y$. pestis EV76 using anaerobic bottles [32]. Of note, the current results strongly supported previous reports that suggested the utility of anaerobic culture conditions in the diagnosis of other blood stream infections (BSI) caused by facultative anaerobes, obligate anaerobic pathogens and even obligate aerobic pathogens [33-35]. Although this later observation may stem from the inadvertent introduction of air into the vials and/or to the rich composition of the medium [36], it may be concluded that the implementation of anaerobic growth conditions in the clinical diagnostic practice in general and specifically for $Y$. pestis is highly beneficial.

A

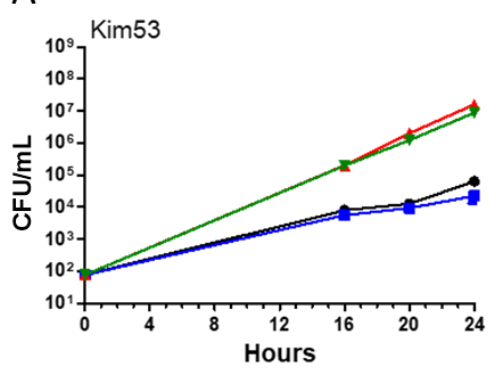

B

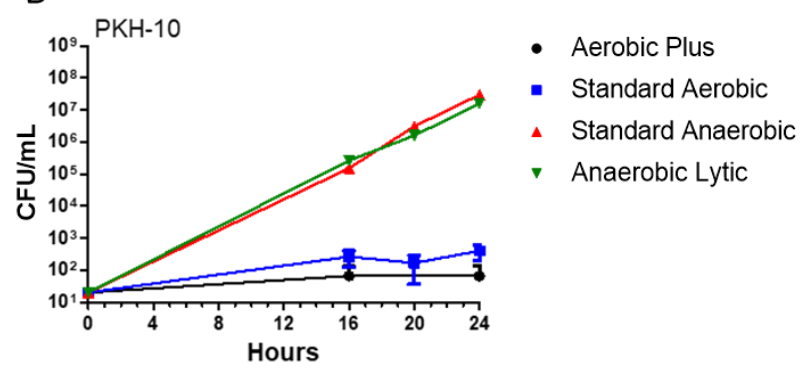

C

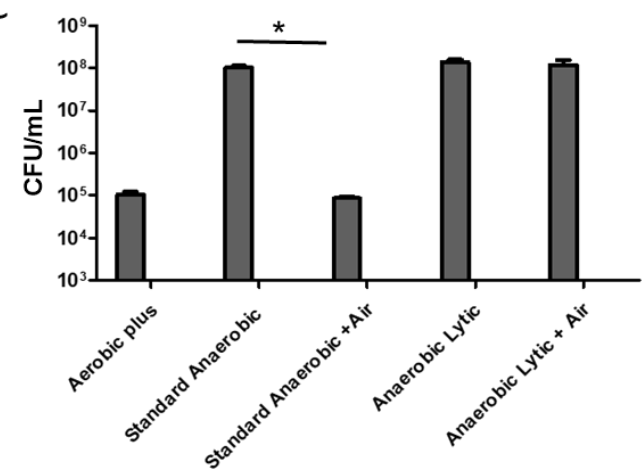

Figure 5. Superior bacterial growth in anaerobic vs. aerobic vials. Aerobic and Anaerobic BACTEC vials (Standard Aerobic, Plus Aerobic, Standard Anaerobic and Anaerobic Lytic) containing $10 \mathrm{~mL}$ of naive fresh human blood were spiked with Kim53 (100 CFU/mL) and PKH-10 $(10 \mathrm{CFU} / \mathrm{mL})$. Vials were incubated at $37^{\circ} \mathrm{C}$ and bacterial growth was determined following 16,20 and $24 \mathrm{~h}$ incubation by CFU counts. A comparison of the natural growth of Kim53 (A) and PKH-10 (B) under aerobic and anaerobic conditions was evaluated. ${ }^{*} p<0.01$ of anaerobic vs. aerobic vials according to a two-way ANOVA test. (C) The role of anaerobic conditions in enhancing Y. pestis growth. Anaerobic BACTEC vials (Standard and Lytic) containing $10 \mathrm{~mL}$ of naive fresh human blood were spiked with Kim53 $(100 \mathrm{CFU} / \mathrm{mL})$. The role of the anaerobic condition in bacterial growth was determined by inserting air into the vials, replacing the $\mathrm{N}_{2} / \mathrm{CO}_{2}$ atmosphere prior to incubation compared with the growth obtained in non-aerated vials. BACTEC Aerobic Plus blood culture was used as a control. Results are averages \pm SEM of three counts of duplicate blood cultures containing two individual blood donations in each group. ${ }^{*} p<0.01$ of standard anaerobic vs. anaerobic + air vials according to a two-tailed Student's $t$-test. 
To evaluate whether the accelerated growth in the anaerobic vials was due to the anaerobic conditions or to the different composition of the media (see Supplementary Table S1), experiments on Kim53 bacteria-spiked standard and lytic anaerobic cultures were performed in the presence of exogenously added air, replacing the original $\mathrm{N}_{2} / \mathrm{CO}_{2}$ atmosphere of the cultures. A significant decrease in the bacterial counts was observed in these modified standard anaerobic vials compared with the non-altered vials (Figure 5C). Interestingly, the bacterial counts in the modified anaerobic culture were comparable with those observed in the Aerobic Plus blood cultures, indicating the importance of anaerobic conditions in accelerating the $Y$. pestis growth rates. In contrast, no effect from the addition of air into the lytic anaerobic cultures was observed, suggesting that the composition was the dominant factor in these vials. This was possibly due to the presence of saponin, which causes hemolysis and an increased availability of red blood cell-derived nutrients (including iron) that support the growth of bacteria.

To further improve the $Y$. pestis growth in anaerobic cultures, we interrogated the effect of supplemented $\mathrm{Fe}^{+2}$ and $\mathrm{Ca}^{+2}$. In contrast to the effect observed in the supplemented aerobic vials, no significant elevation in the bacterial counts was observed for the supplemented anaerobic cultures (Figure 6A,B). Comparing the bacterial counts obtained in the anaerobic cultures with the aerobic cultures supplemented with $\mathrm{Fe}^{+2}$ and $\mathrm{Ca}^{+2}$, we established that the latter conditions resulted in an order of magnitude increase in the bacterial counts $(24 \mathrm{~h}$ incubation, Figure $6 \mathrm{C}, \mathrm{D})$. The calculation of the doubling time in the log-phase (Figure 6A,B) showed that the shorter doubling time characterizing the anaerobic growth was similar to that observed in the supplemented aerobic conditions (45 min). The higher total bacterial counts observed in the supplemented aerobic vs. the anaerobic conditions could reflect a shortened lag phase. Long lag phases may be expected to be more pronounced when the initial inoculum is low.

A

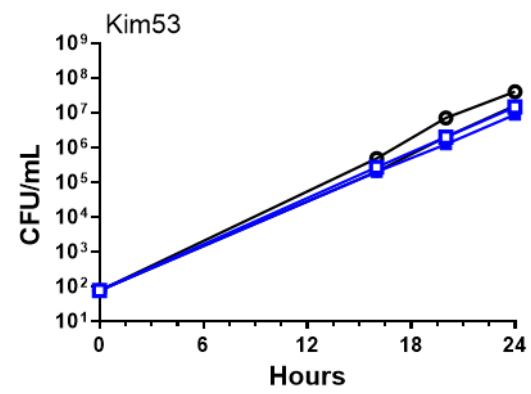

C

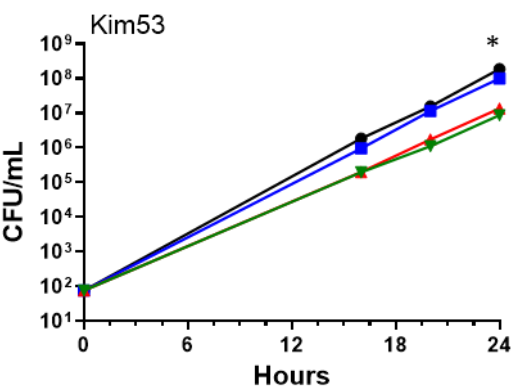

B

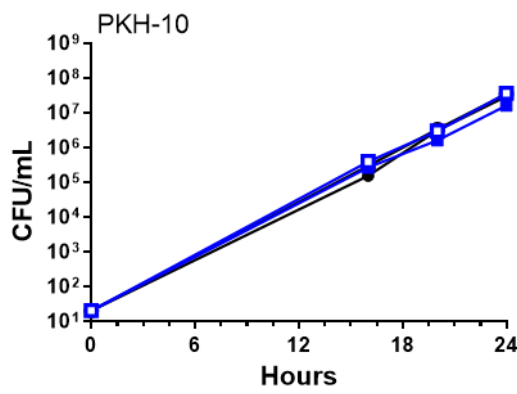

D

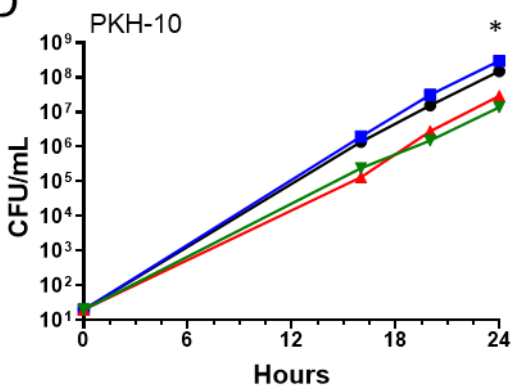

- Standard Anaerobic

- Standard Anaerobic + Ca \& Fe

- Anaerobic Lytic

- Anaerobic Lytic + Ca \& Fe

Figure 6. Superior bacterial growth in supplemented aerobic vs. anaerobic vials. Aerobic and Anaerobic BACTEC vials (Standard Aerobic, Plus Aerobic, Standard Anaerobic and Anaerobic Lytic) containing $10 \mathrm{~mL}$ of naive fresh human blood were spiked with Kim53 (100 CFU/mL) and PKH-10 $(10 \mathrm{CFU} / \mathrm{mL})$. Vials were incubated at $37^{\circ} \mathrm{C}$ and bacterial growth was determined following 16,20 and $24 \mathrm{~h}$ incubation by CFU counts. $(\mathbf{A}, \mathbf{B})$ The role of supplemented $\mathrm{Ca}^{+2}(2.5 \mathrm{mM})$ and $\mathrm{Fe}^{+2}(100 \mu \mathrm{M})$ in anaerobic cultures was evaluated. Non-supplemented anaerobic vials were used as a control. (C,D) A 
superior increase in bacterial counts was achieved in aerobic supplemented vs. anaerobic cultures. Results are averages \pm SEM of three counts each of duplicate blood cultures containing two individual blood donations in each group and represent two independent experiments obtaining similar results. ${ }^{*} p<0.01$ of supplemented aerobic vs. non-supplemented anaerobic vials according to a two-way ANOVA test.

\subsection{Accurate Identification and Antibiotic Susceptibility Testing of Y. pestis in Supplemented Blood Cultures}

For plague diagnosis, blood samples of suspected infected individuals are examined for the presence of the soluble capsular antigen (F1) and V antigen, the major bacterial virulence factors [10,37-39]. As these biomarkers are considered to be reliable and specific for an early detection, their presence in the modified cultures was further assessed. Supplemented and non-supplemented BACTEC Aerobic Plus blood cultures were spiked with bacteria of the Kim53 or PKH-10 virulent strains. The culture samples were collected at 16-24 $\mathrm{h}$ incubation and the levels of F1 and V antigens were determined by an ELISA. The early detection of F1 and V was observed for both strains in the supplemented media in correlation with the accelerated growth rates promoted by metal ion supplementation. The maximal detection values (assay saturation) for F1 were quantified as early as $16 \mathrm{~h}$ postinoculation in the supplemented cultures compared with the marginal values (borderline positive) detected after $20 \mathrm{~h}$ (with Kim53) or even undetectable levels after $24 \mathrm{~h}$ (PKH-10) in the non-supplemented cultures (Figure 7A,C). Surprisingly, the V antigen was detectable in the supplemented cultures after $16 \mathrm{~h}$ (both strains) compared with a minimal to no detection in the non-supplemented cultures after $24 \mathrm{~h}$ incubation (Figure 7B,D). The $\mathrm{V}$ antigen elevation in the $\mathrm{Ca}^{+2}$-supplemented culture did not align with the low calcium response mechanism of $Y$. pestis. This could possibly be explained by a differential response to the combination of $\mathrm{Fe}^{+2}$ and $\mathrm{Ca}^{+2}$ compared with $\mathrm{Ca}^{+2}$ alone, exerting different effects on the gene regulation [40]. This phenomenon was also determined following $24 \mathrm{~h}$ in the cultures of the bacteria belonging to the Alexander and IV 75195 virulent strains (Figure 7E,F). The early detection of the F1 and V antigens directly from the blood cultures strengthened the significant improvement promoted by $\mathrm{Fe}^{+2}$ and $\mathrm{Ca}^{+2}$ supplementation as accelerators of growth for diagnostic purposes. We envisage that, in the future, using supplemented cultures may represent a means by which soluble antigen detection is implemented as a standalone assay for an even more rapid plague identification in blood culture.

Finally, we verified that supplementing the growth media did not detrimentally affect the reliability of the additional diagnostic tests either for directly identifying $Y$. pestis or for antibiotic susceptibility testing (AST). First, the performance of MALDI-TOF MS in the identification of the pathogen was evaluated. This rapid identification methodology has been proposed to represent a reliable diagnostic approach in positive blood cultures using in-house or commercial protein extraction methods [41,42]. As expected, a positive identification with high score values $(>2.1)$ was obtained for the bacterial protein extracts derived from the supplemented blood cultures within $24 \mathrm{~h}$ of incubation but not from the non-supplemented bacterial extracts (which required a $40 \mathrm{~h}$ incubation for identification). Of note, this result suggested that the potential modification of the media did not alter the Y. pestis protein repertoire, allowing the MALDI-TOF identification (Figure 8A). The anti-F1 immunofluorescence staining method for a $Y$. pestis diagnosis in the blood culture samples was then tested. The results, as described in Figure 8B, established that the sensitivity of the assay actually improved, owing to the higher bacterial density afforded by the supplemented cultures (Figure 8B). Finally, the supplemented blood cultures were used as a bacterial source for AST. Several antibiotics are recommended by the Center For Disease And Prevention Control (CDC) for prophylaxis and the treatment of plague [43] including bacteriostatic (e.g., doxycycline) and bactericidal drugs (e.g., ciprofloxacin and gentamicin). Of note, a spontaneous resistance to therapeutic antibiotics rarely emerges in $Y$. pestis, yet the malicious use of this pathogen in bio-terror scenarios may be associated with the 
intentional engineering of strains exhibiting a resistance; therefore, the ease of isolation promoted by the modified cultures is beneficial.
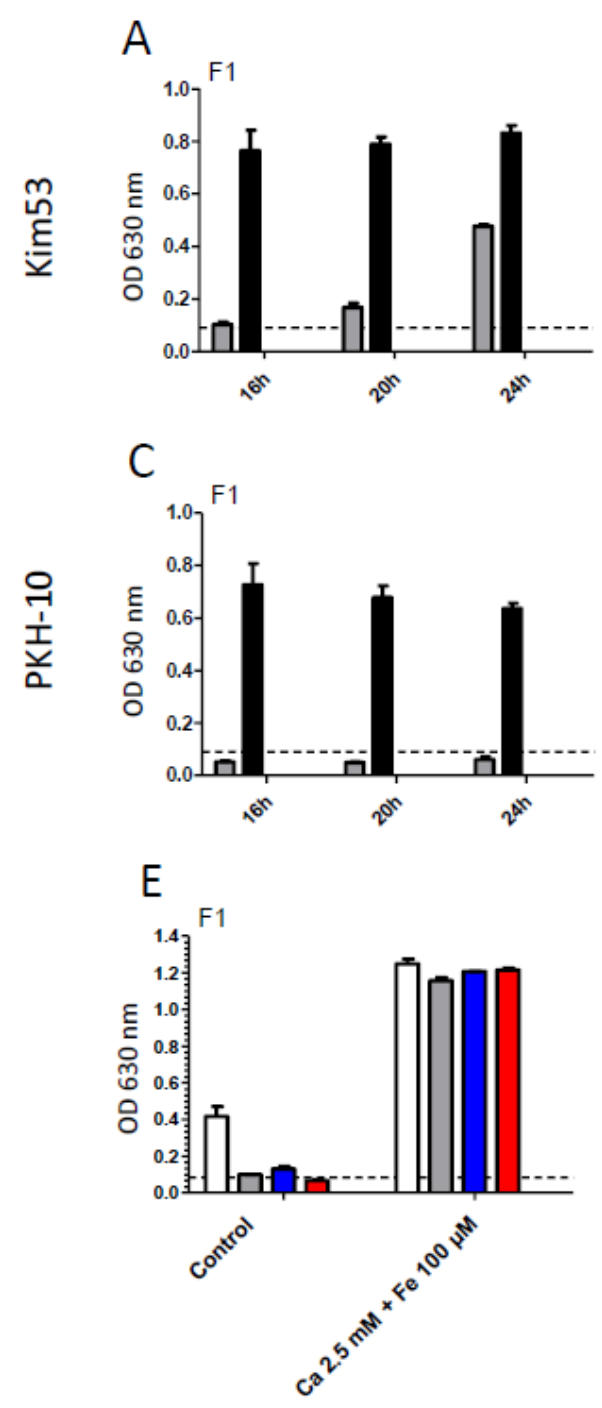

B

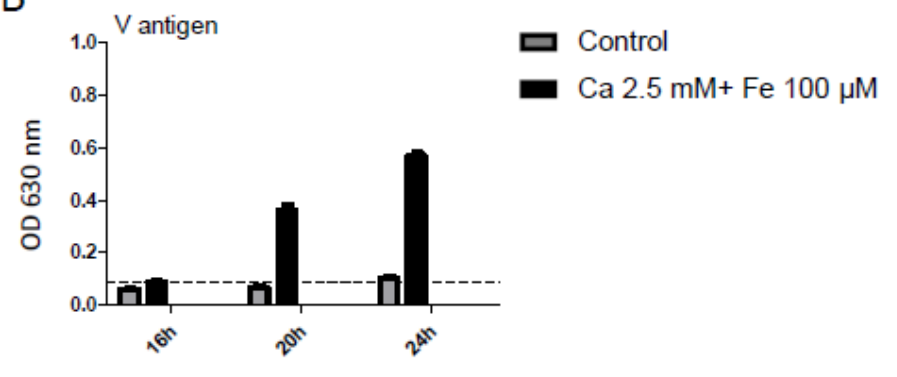

D

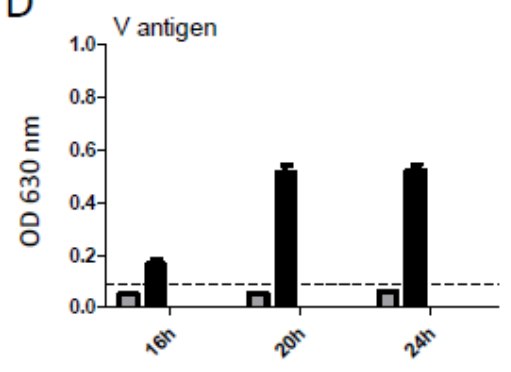

$\mathrm{F}$

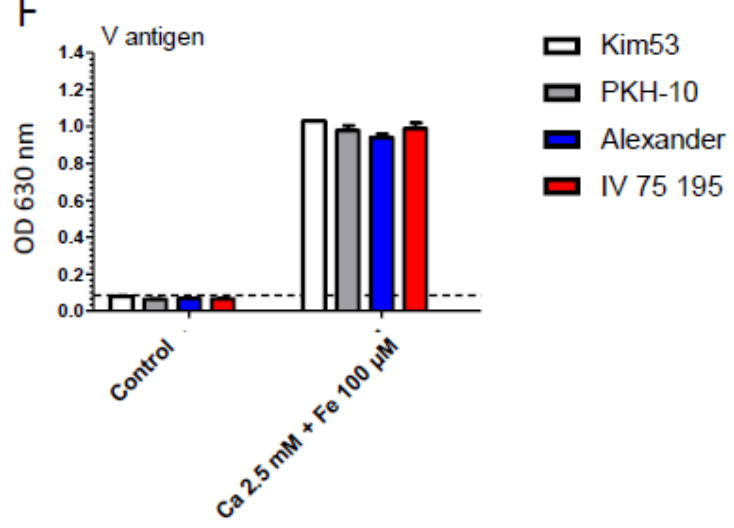

Figure 7. Detection of plague virulence biomarkers V and F1 antigens from inoculated blood culture. Blood cultures (BACTEC Plus Aerobic/F culture vials) containing $10 \mathrm{~mL}$ of naive fresh human blood were spiked with $(\mathbf{A}, \mathbf{B}) \mathrm{Kim} 53(500 \mathrm{CFU} / \mathrm{mL})$ and $(\mathbf{C}, \mathbf{D}) \mathrm{PKH}-10(100 \mathrm{CFU} / \mathrm{mL}) . \mathrm{Ca}^{+2}(2.5 \mathrm{mM})$ and $\mathrm{Fe}^{+2}(100 \mu \mathrm{M})$ were supplemented into vials. Non-supplemented blood cultures were used as a control. Vials were incubated at $37^{\circ} \mathrm{C}$ and blood cultures were sampled following 16, 20 and $24 \mathrm{~h}$ incubation for the detection of plague biomarkers F1 and V antigens by ELISA. (E,F) F1 and $\mathrm{V}$ antigen detection following $24 \mathrm{~h}$ incubation of blood culture inoculated with four different virulent Y. pestis strains (Kimberley53, PKH-10, Alexander and IV 75 195) at a final concentration of 10-500 CFU/mL. Black dashed line represents OD $630 \mathrm{~nm} 0.1$, the limit of detection of the test. Results are averages \pm SEM of triplicates of two blood cultures in each group containing two individual blood donations. 
A

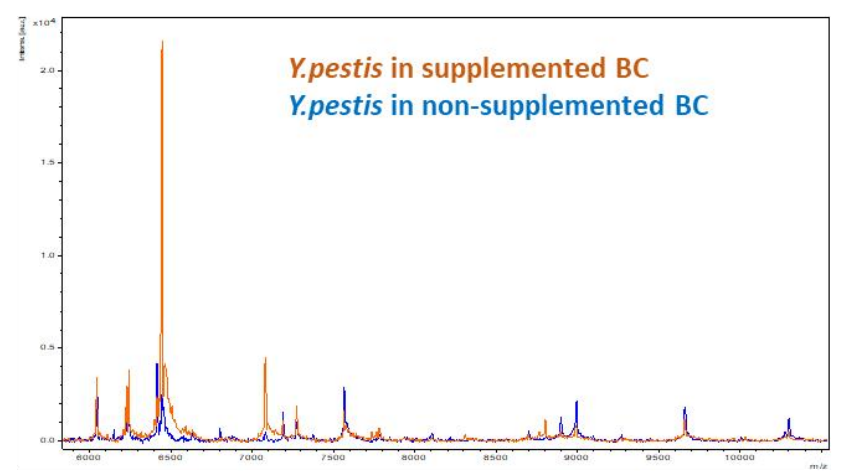

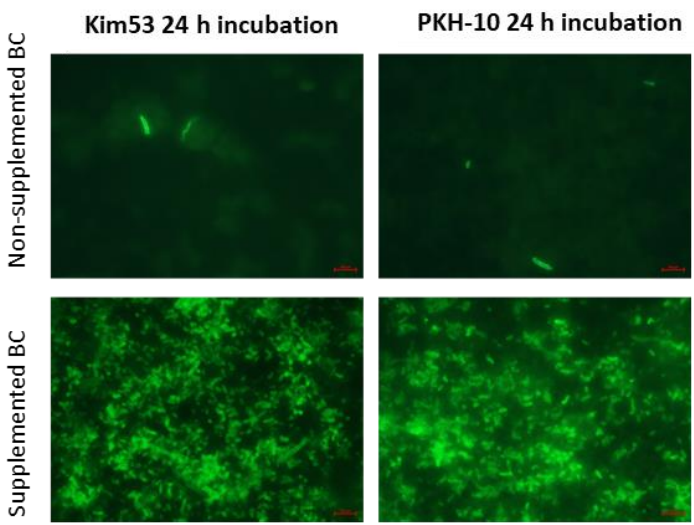

C

\begin{tabular}{cccc}
\hline MIC test sample & $\begin{array}{c}\text { Ciprofloxacin } \\
(\mu \mathrm{g} / \mathrm{ml})\end{array}$ & $\begin{array}{c}\text { Doxycycline } \\
(\mu \mathrm{g} / \mathrm{ml})\end{array}$ & $\begin{array}{c}\text { Gentamicin } \\
(\mu \mathrm{g} / \mathrm{ml})\end{array}$ \\
\hline Standard control & $0.016-0.032$ & $0.25-0.38$ & $1-1.5$ \\
\hline Supplemented BC & 0.016 & $0.25-0.38$ & 1.5 \\
\hline
\end{tabular}

Figure 8. Direct detection and susceptibility assays for $Y$. pestis in supplemented blood cultures. BACTEC Plus Aerobic/F culture vials containing $10 \mathrm{~mL}$ of naive fresh human blood were spiked with Kim53 and PKH-10. $\mathrm{Ca}^{+2}(2.5 \mathrm{mM})$ and $\mathrm{Fe}^{+2}(100 \mu \mathrm{M})$ were supplemented into vials and nonsupplemented blood cultures (BC) were used as a control. (A) MALDI-TOF analysis of Kim53 bacterial protein extraction derived directly from supplemented and non-supplemented cultures following $24 \mathrm{~h}$ and $40 \mathrm{~h}$ incubation, respectively. Spectrum obtained from a protein extract derived from supplemented culture completely overlapped with the spectrum obtained from non-supplemented control culture (orange and blue spectra, respectively). (B) Immunofluorescence assay (IFA) using A488-conjugated anti-Y. pestis F1 polyclonal Abs for the detection of the bacteria directly from blood culture following $24 \mathrm{~h}$ incubation. (C) E-test assays to determine the MIC $(\mu \mathrm{g} / \mathrm{mL})$ of ciprofloxacin, doxycycline and gentamicin were performed directly from supplemented blood cultures (following $24 \mathrm{~h}$ incubation) and compared with standard tests (performed using bacteria suspended in PBS and plated).

Antibiogram E-test assays were performed in order to examine whether the $\mathrm{Fe}^{+2}$ and $\mathrm{Ca}^{+2}$ supplementation affected the susceptibility of the bacteria to these antibiotics compared with the non-supplemented culture. Therefore, the minimal inhibitory concentration (MIC) of $Y$. pestis derived from the supplemented compared with the non-supplemented blood cultures was determined. The lower density of the bacteria in the non-supplemented media following $24 \mathrm{~h}$ of incubation impaired the reliability of the test whereas in the supplemented media, the MIC was successfully determined with no differences in values compared with the standard test as the control (Figure $8 \mathrm{C}$ ). Thus, the results clearly indicated the highly beneficial value of supplementing the cultures for the rapid diagnosis and isolation of $Y$. pestis.

\section{Conclusions}

Blood culturing represents the routine method for a bloodstream infection diagnosis. This is especially relevant considering the low specificity of the clinical presentation at the beginning of a $Y$. pestis infection. In the case of outbreaks occurring in geographic locations that do not have the benefit of well-stocked diagnostics laboratories, blood culturing may be limited in feasibility but it has an important role in molecular epidemiology surveillance and antimicrobial resistance monitoring. The conclusive identification of slow growth pathogens using blood culture methods frequently requires more than $24 \mathrm{~h}$ (up to $96 \mathrm{~h}$ ). 
The delays in the detection and proper identification can affect the efficacy of the treatments whose early administration is critical, especially in the case of lethal pathogens such as Yersinia pestis $[5,44]$. In the present study, $Y$. pestis was representative of slow growing bacteria in vitro. In order to shorten the diagnostic time, adding external $\mathrm{Fe}^{+2}$ and $\mathrm{Ca}^{+2}$ to commercially routinely used blood culture vials was examined for the ability of enhancing the $Y$. pestis growth rates, allowing a rapid diagnosis.

The study consisted of a comparison of a variety of blood culturing conditions generated by supplemented or standard aerobic and anaerobic protocols. The data documented in this report established a significant improvement in the rate of bacterial growth in combined $\mathrm{Fe}^{+2}$ - and $\mathrm{Ca}^{+2}$-supplemented media. The study suggested that the supplemented aerobic cultures represented the conditions of choice for the early detection of the pathogen both on the basis of the bacterial growth as well as the methods involving mass spectrometry, immunodetection and the quantification of the soluble bacteria-derived biomarkers.

We recommend that, in suspected plague cases, either anaerobic (as per the original protocol) or supplemented aerobic vials should be included in the sampling protocol. In such cases, positive BACTEC signals may prompt early downstream diagnostic assays for $Y$. pestis identification. Further research will establish the applicability of the metal ion supplementation for the improvement of the growth of other pathogens, possibly leading to a general universal method for accelerating the pathogen growth and identification.

\section{Materials and Methods}

\subsection{Y. pestis Strains}

Frozen bacterial stocks were prepared by growing several Y. pestis colonies that carried the pMT1, pCD1 or pPCP1 plasmids and the pgm locus in Tryptose Phosphate Broth (TPB, BD 260300) for $20 \mathrm{~h}$ in a shaking incubator $(100 \mathrm{rpm})$ at $28^{\circ} \mathrm{C}$. Glycerol was added to a final concentration of $15 \%$ and the cultures were stored at $-70{ }^{\circ} \mathrm{C}$.

The study was conducted in a BSL3 facility in accordance with the biosafety guidelines of the Israel Institute for Biological Research (IIBR).

Table 1. Y. pestis Strains.

\begin{tabular}{ccc}
\hline Strain & Biovar & Ref. \\
\hline Kimberley53 (Kim53) & Orientalis & {$[19]$} \\
Alexander & Orientalis & {$[11]$} \\
PKH-10 & Medievalis & This study \\
IV 75 195 & Orientalis & {$[11]$} \\
\hline
\end{tabular}

\subsection{Culture Media}

A $1 \mathrm{M}$ solution of calcium chloride was obtained from Sigma Israel. $\mathrm{FeSO}_{4}$ powder (obtained from Merck) was freshly dissolved in DDW, reaching a $100 \mathrm{mM}$ stock solution and was then filtered in a $0.2 \mu \mathrm{m}$ filter. Human blood samples were obtained from the National Blood Services, MDA, Israel, under MDA research permit 08-0290.

Y. pestis strains were grown on BHIA (brain heart infusion agar, BD, Sparks, MD, USA) plates at $37^{\circ} \mathrm{C}$ for $48 \mathrm{~h}$. The colonies were suspended in sterile phosphate-buffered saline (PBS, Biological Industries, Beth Haemek, Israel) and added at a defined concentration into naïve fresh human blood. Th inoculated blood samples $(10 \mathrm{~mL} / \mathrm{vial})$ were inserted into four different BACTECTM blood culture vials (Plus Aerobic/F, Standard Aerobic/F, Standard Anaerobic/F and Lytic Anaerobic/F) (BD, Sparks, MD, USA). The blood cultures were supplemented with $\mathrm{CaCl}_{2}$ and $\mathrm{FeSO}_{4}$ at a final concentration of $2.5 \mathrm{mM}$ and $100 \mu \mathrm{M}$, respectively. The non-supplemented blood culture vials were used as a control. The inoculated blood culture vials were then shaken at $150 \mathrm{rpm}$ at $37^{\circ} \mathrm{C}$ in a New Brunswick Scientific C76 water bath for the indicated time periods. The initial CFU counts (time zero) were determined by plating $0.1 \mathrm{~mL}$ blood culture samples of serial 10-fold dilutions in 
duplicate; for additional time points, drop-plating was performed by plating 5-10 $\mu \mathrm{L}$ of serial 10-fold dilutions in triplicate on BHIA plates. The colony-forming unit (CFU) was determined following a $48 \mathrm{~h}$ incubation at $28^{\circ} \mathrm{C}$. Each experiment was conducted using at least two different human blood samples collected from distinct donors. The samples were equally distributed in $2-4$ blood culture vials generating duplicates within each group per strain. A total of 12 different blood donations were used in this study.

\subsection{MIC Determination}

E-test strips (BioMerieux, Craponne, France) of selected antimicrobial agents (ciprofloxacin, doxycycline and gentamicin) were applied to an inoculated Mueller-Hinton $(\mathrm{MH})$ agar surface derived from spiked blood cultures (BCs) with or without supplements. Each strip contained dried antibiotic concentration gradients that were marked with a concentration scale. The plates were incubated for $24 \mathrm{~h}$ at $28^{\circ} \mathrm{C}$. The MIC (minimal inhibitory concentration) values $(\mu \mathrm{g} / \mathrm{mL})$ were read directly from the strips according to the manufacturer's instructions.

\subsection{Immunofluorescence Assay (IFA) for Y. pestis Detection}

The IFA assay allowed the visualization of the bacteria in different matrixes. A total of $2 \mu \mathrm{L}$ of inoculated BC with or without supplements was applied onto slides, air dried and fixed in $10 \%$ formalin for $30 \mathrm{~min}$. An Alexa 488-conjugated anti-Y. pestis polyclonal antibody $(5 \mu \mathrm{L})$ [45] was applied on the spots and incubated at $37^{\circ} \mathrm{C}$ for $30 \mathrm{~min}$. After washing with tap water, the spots were visualized by a fluorescent microscope equipped with a green filter (excitation: $475 \mathrm{~nm} /$ emission: $530 \mathrm{~nm}$ ). The bacteria were visualized in $\times 400$ magnification using an Axioskop (Zeiss Thornwood, Thornwood, NY, USA) and a DS-iR1 camera (Nikon, Melville, NY, USA). The images were taken using NIS-elements software (Nikon, Melville, NY, USA).

\subsection{Detection of F1 and V Antigens from Inoculated Blood Cultures by ELISA}

Microtiter plates were coated with $5 \mu \mathrm{g} / \mathrm{mL}$ polyclonal antibodies against $\mathrm{F} 1$ and $\mathrm{V}$ antigens separately [46] overnight at $4{ }^{\circ} \mathrm{C}$. The coated wells were blocked with $2 \%$ BSA for $2 \mathrm{~h}$ at $37^{\circ} \mathrm{C}$. In order to detect the $\mathrm{F} 1$ and $\mathrm{V}$ antigens, $1 \mathrm{~mL}$ of the inoculated $\mathrm{BC}$ (with or without supplements) was spun at 14,000 rpm for $5 \mathrm{~min}$. A total of $50 \mu \mathrm{L}$ from the supernatant was applied on the microtiter plates and incubated for $30 \mathrm{~min}$ at $37^{\circ} \mathrm{C}$ following the washing step with PBS containing $0.05 \%$ Tween 20 . Secondary Horseradish Peroxidase (HRP)-conjugated polyclonal anti-F1 or V antibodies were added and the plate was incubated at $37^{\circ} \mathrm{C}$ for $30 \mathrm{~min}$. Following an additional wash step, $50 \mu \mathrm{L}$ of tetramethylbenzidine (TMB, Sigma, Jerusalem, Israel) was added to each well and the plate was incubated at room temperature for $20 \mathrm{~min}$. The absorbance was measured at a $630 \mathrm{~nm}$ wavelength.

\subsection{Bacterial Identification by MALDI-TOF MS}

A direct bacterial identification using an MBT Sepsityper ${ }^{\circledR}$ IVD kit (Bruker Daltonics $\mathrm{GmbH}$, Bremen, Germany) was performed according to the manufacturer's instructions. Briefly, $1 \mathrm{~mL}$ of blood culture fluid was collected and transferred into a $1.5 \mathrm{~mL}$ tube followed by the addition of a $200 \mu \mathrm{L}$ lysis buffer. The mix was centrifuged for $2 \mathrm{~min}$ at 14,000 rpm and the pellet was washed with a $1 \mathrm{~mL}$ washing buffer. The mix was re-centrifuged for $1 \mathrm{~min}$ at 14,000 rpm. The supernatant was discarded and the pellet was dried. The proteins of the sample were extracted using a standard EX method according to the manufacturer's instructions. The samples were then identified by a Bruker MALDI-TOF MS instrument (Bruker Daltonics, GmbH, Bremen, Germany). 


\subsection{Statistical Analysis}

The data were analyzed using GraphPad Prism5 software. The results were expressed as a mean \pm standard error. The statistical significance was determined by a Student's $t$-test and a two-way ANOVA. A $p$-value $\leq 0.05$ was considered to be significant.

Supplementary Materials: The following are available online at https:/ /www.mdpi.com/article/10 .3390 / pathogens11020255/s1, Table S1: BACTEC blood culture ingredients.

Author Contributions: Conceptualization, E.M. (Efi Makdasi), E.M. (Emanuelle Mamroud) and A.Z.; methodology, E.M. (Efi Makdasi), Y.A.-N., E.M. (Elad Milrot), S.S., H.L., D.G. and A.Z.; software, E.M. (Efi Makdasi) and O.S.; validation, E.M. (Efi Makdasi), Y.A.-N., D.G. and A.Z.; formal analysis, E.M. (Efi Makdasi); investigation, E.M. (Efi Makdasi), Y.A.-N., O.L. and E.M. (Emanuelle Mamroud); resources, S.W. and S.S.; writing-original draft preparation, E.M. (Efi Makdasi), I.G. and T.C.; writing-review and editing, E.M. (Emanuelle Mamroud), Y.A.-N., O.L. and O.S.; visualization, E.M. (Efi Makdasi). All authors have read and agreed to the published version of the manuscript.

Funding: This research received no external funding.

Institutional Review Board Statement: Human blood samples were obtained from the National Blood Services, MDA, Israel, under MDA research permit 08-0290.

Informed Consent Statement: Informed consent was obtained from all subjects involved in the study.

Acknowledgments: This study was supported by the Israel Institute for Biological Research.

Conflicts of Interest: The authors declare no conflict of interest.

\section{References}

1. Respicio-Kingry, L.B.; Yockey, B.M.; Acayo, S.; Kaggwa, J.; Apangu, T.; Kugeler, K.J.; Eisen, R.J.; Griffith, K.S.; Mead, P.S.; Schriefer, M.E.; et al. Two Distinct Yersinia pestis Populations Causing Plague among Humans in the West Nile Region of Uganda. PLoS Negl. Trop. Dis. 2016, 10, e0004360. [CrossRef] [PubMed]

2. Shi, L.Y.; Ding, Y.B.; Tan, H.L.; Guo, Y.; Zhang, H.P.; Duan, C.J.; Li, W.; Wang, P. Source tracing of the Yersinia pestis strains isolated from Heqing county, Yunnan province in 2017. Zhonghua Liu Xing Bing Xue Za Zhi 2018, 39, 983-987. [PubMed]

3. Abedi, A.A.; Shako, J.-C.; Gaudart, J.; Sudre, B.; Ilunga, B.K.; Shamamba, S.K.B.; Diatta, G.; Davoust, B.; Tamfum, J.-J.M.; Piarroux, R.; et al. Ecologic Features of Plague Outbreak Areas, Democratic Republic of the Congo, 2004-2014. Emerg. Infect. Dis. 2018, 24, 210-220. [CrossRef] [PubMed]

4. Randremanana, R.; Andrianaivoarimanana, V.; Nikolay, B.; Ramasindrazana, B.; Paireau, J.; Bosch, Q.A.T.; Rakotondramanga, J.M.; Rahajandraibe, S.; Rahelinirina, S.; Rakotomanana, F.; et al. Epidemiological characteristics of an urban plague epidemic in Madagascar, August-November, 2017: An outbreak report. Lancet Infect. Dis. 2019, 19, 537-545. [CrossRef]

5. Inglesby, T.V.; Dennis, D.T.; Henderson, D.A.; Bartlett, J.G.; Ascher, M.S.; Eitzen, E.; Fine, A.D.; Friedlander, A.M.; Hauer, J.; Koerner, J.F.; et al. Plague as a biological weapon: Medical and public health management. JAMA 2000, 283, 2281-2290. [CrossRef]

6. Towns, M.L.; Jarvis, W.R.; Hsueh, P.R. Guidelines on Blood Cultures. J. Microbiol. Immunol. Infect. 2010, 43, 347-349. [CrossRef]

7. Aftalion, M.; Aloni-Grinstein, R.; Andrianaivoarimanana, V.; Iharisoa, A.L.; Shmaya, S.; Gur, D.; Laskar, O.; Rajerison, M.; Mamroud, E. Improved Selective BIN Agar for a Better Rate of Yersinia pestis Isolation from Primary Clinical Specimens in Suspected Madagascar Plague Cases. J. Clin. Microbiol. 2021, 59, e0056421. [CrossRef]

8. Ber, R.; Mamroud, E.; Aftalion, M.; Gur, D.; Tidhar, A.; Flashner, Y.; Cohen, S. A new selective medium provides improved growth and recoverability of Yersinia pestis. Adv. Exp. Med. Biol. 2003, 529, 467-468.

9. Ber, R.; Mamroud, E.; Aftalion, M.; Tidhar, A.; Gur, D.; Flashner, Y.; Cohen, S. Development of an improved selective agar medium for isolation of Yersinia pestis. Appl. Environ. Microbiol. 2003, 69, 5787-5792. [CrossRef]

10. Mechaly, A.; Vitner, E.; Levy, H.; Weiss, S.; Bar-David, E.; Gur, D.; Koren, M.; Cohen, H.; Cohen, O.; Mamroud, E.; et al. Simultaneous Immunodetection of Anthrax, Plague, and Tularemia from Blood Cultures by Use of Multiplexed Suspension Arrays. J. Clin. Microbiol. 2018, 4, 56. [CrossRef]

11. Mechaly, A.; Vitner, E.; Levy, Y.; Gur, D.; Barlev-Gross, M.; Sittner, A.; Koren, M.; Levy, H.; Mamroud, E.; Fisher, M. Epitope Binning of Novel Monoclonal Anti F1 and Anti LcrV Antibodies and Their Application in a Simple, Short, HTRF Test for Clinical Plague Detection. Pathogens 2021, 10, 285. [CrossRef]

12. Moses, S.; Aftalion, M.; Mamroud, E.; Rotem, S.; Steinberger-Levy, I. Reporter-Phage-Based Detection and Antibiotic Susceptibility Testing of Yersinia pestis for a Rapid Plague Outbreak Response. Microorganisms 2021, 9, 1278. [CrossRef]

13. Moses, S.; Aftalion, M.; Mamroud, E.; Rotem, S.; Steinberger-Levy, I. Characterization of Yersinia pestis Phage Lytic Activity in Human Whole Blood for the Selection of Efficient Therapeutic Phages. Viruses 2021, 13, 89. [CrossRef] 
14. Vandamm, J.P.; Rajanna, C.; Sharp, N.J.; Molineux, I.J.; Schofield, D.A. Rapid detection and simultaneous antibiotic susceptibility analysis of Yersinia pestis directly from clinical specimens by use of reporter phage. J. Clin. Microbiol. 2014, 52, 2998-3003. [CrossRef]

15. Israeli, O.; Makdasi, E.; Cohen-Gihon, I.; Zvi, A.; Lazar, S.; Shifman, O.; Levy, H.; Gur, D.; Laskar, O.; Beth-Din, A. A rapid high-throughput sequencing-based approach for the identification of unknown bacterial pathogens in whole blood. Futur. Sci. $O A$ 2020, 6, FSO476. [CrossRef]

16. McHugh, J.P.; Rodríguez-Quiñones, F.; Abdul-Tehrani, H.; Svistunenko, D.A.; Poole, R.K.; Cooper, C.E.; Andrews, S.C. Global iron-dependent gene regulation in Escherichia coli. A new mechanism for iron homeostasis. J. Biol. Chem. 2003, 278, 29478-29486. [CrossRef]

17. Litwin, C.M.; Calderwood, S.B. Role of iron in regulation of virulence genes. Clin. Microbiol. Rev. 1993, 6, 137-149. [CrossRef]

18. Schaible, U.E.; Kaufmann, S.H. Iron and microbial infection. Nat. Rev. Microbiol. 2004, 2, 946-953. [CrossRef]

19. Zauberman, A.; Vagima, Y.; Tidhar, A.; Aftalion, M.; Gur, D.; Rotem, S.; Chitlaru, T.; Levy, Y.; Mamroud, E. Host Iron Nutritional Immunity Induced by a Live Yersinia pestis Vaccine Strain Is Associated with Immediate Protection against Plague. Front. Cell. Infect. Microbiol. 2017, 7, 277. [CrossRef]

20. Avanian, L.A.; Gubina, N.E. Effect of iron on the growth of virulent plague microbes. J. Mikrobiol. Epidemiol. Immunobiol. 1961, 32, 92-97.

21. Kravtsov, A.N.; Tynianova, V.I.; Ziuzina, V.P. An increase in the virulence of Yersinia pestis bacteria when the cells are incubated in hemolyzed human erythrocytes. J. Mikrobiol. Epidemiol. Immunobiol. 1993, 1993, 3-6.

22. Tsukano, H.; Yamamoto, M.; Wake, A. The effect of an iron drug on the growth of plague microorganisms in vitro and in guinea pig skin. Jpn. J. Med. Sci. Biol. 1972, 25, 85-93. [CrossRef] [PubMed]

23. Sample, A.K.; Fowler, J.M.; Brubaker, R.R. Modulation of the low-calcium response in Yersinia pestis via plasmid-plasmid interaction. Microb. Pathog. 1987, 2, 443-453. [CrossRef]

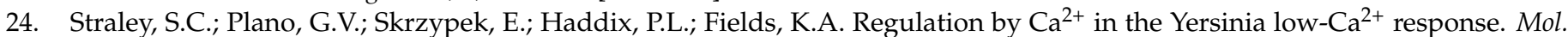
Microbiol. 1993, 8, 1005-1010. [CrossRef]

25. Fowler, J.M.; Brubaker, R.R. Physiological basis of the low calcium response in Yersinia pestis. Infect. Immun. 1994, 62, 5234-5241. [CrossRef]

26. Mehigh, R.J.; Sample, A.K.; Brubaker, R.R. Expression of the low calcium response in Yersinia pestis. Microb. Pathog. 1989, 6, 203-217. [CrossRef]

27. Price, S.B.; Cowan, C.; Perry, R.D.; Straley, S.C. The Yersinia pestis V antigen is a regulatory protein necessary for Ca2(+)-dependent growth and maximal expression of low-Ca2+ response virulence genes. J. Bacteriol. 1991, 173, 2649-2657. [CrossRef]

28. Cockerill, F.R., 3rd; Wilson, J.W.; Vetter, E.A.; Goodman, K.M.; Torgerson, C.A.; Harmsen, W.S.; Schleck, C.D.; Ilstrup, D.M.; Washington, J.A., II; Wilson, W.R. Optimal testing parameters for blood cultures. Clin. Infect. Dis. 2004, 38, 1724-1730. [CrossRef]

29. Weinstein, M.P. Current blood culture methods and systems: Clinical concepts, technology, and interpretation of results. Clin. Infect. Dis. 1996, 23, 40-46. [CrossRef]

30. Grohs, P.; Mainardi, J.-L.; Podglajen, I.; Hanras, X.; Eckert, C.; Buu-Hoï, A.; Varon, E.; Gutmann, L. Relevance of routine use of the anaerobic blood culture bottle. J. Clin. Microbiol. 2007, 45, 2711-2715. [CrossRef]

31. Reimer, L.G.; Wilson, M.L.; Weinstein, M.P. Update on detection of bacteremia and fungemia. Clin. Microbiol. Rev. 1997, 10, 444-465. [CrossRef]

32. Shifman, O.; Aminov, T.; Aftalion, M.; Gur, D.; Cohen, H.; Bar-David, E.; Cohen, O.; Mamroud, E.; Levy, H.; Aloni-Grinstein, R.; et al. Evaluation of the European Committee on Antimicrobial Susceptibility Testing Guidelines for Rapid Antimicrobial Susceptibility Testing of Bacillus anthracis-, Yersinia pestis and Francisella tularensis-Positive Blood Cultures. Microorganisms 2021, 9, 1055. [CrossRef] [PubMed]

33. Guajardo-Lara, C.E.; Saldaña-Ramírez, M.I.; Ayala-Gaytán, J.J.; Valdovinos-Chávez, S.B. Role of anaerobic blood culture in the simultaneous blood culture taking for the diagnosis of bacteremia. Rev. Med. Inst. Mex. Seguro. Soc. 2016, 54, $292-296$.

34. Lafaurie, M.; D’Anglejan, E.; Donay, J.L.; Glotz, D.; Sarfati, E.; Mimoun, M.; Legrand, M.; Oksenhendler, E.; Bagot, M.; Valade, S.; et al. Utility of anaerobic bottles for the diagnosis of bloodstream infections. BMC Infect. Dis. 2020, 20, 142. [CrossRef] [PubMed]

35. Li, G.; Sun, J.; Pan, S.; Li, W.; Zhang, S.; Wang, Y.; Sun, X.; Xu, H.; Ming, L. Comparison of the Performance of Three Blood Culture Systems in a Chinese Tertiary-Care Hospital. Front. Cell. Infect. Microbiol. 2019, 9, 285. [CrossRef] [PubMed]

36. Rohner, P.; Pepey, B.; Auckenthaler, R. Advantage of combining resin with lytic BACTEC blood culture media. J. Clin. Microbiol. 1997, 35, 2634-2638. [CrossRef]

37. Leal, N.C.; Almeida, A.M. Diagnosis of plague and identification of virulence markers in Yersinia pestis by multiplex-PCR. Rev. Inst. Med. Trop. 1999, 41, 339-342. [CrossRef]

38. Nikiforov, V.V.; Gao, H.; Zhou, L.; Anisimov, A. Plague: Clinics, Diagnosis and Treatment. Adv. Exp. Med. Biol. 2016, 918, $293-312$.

39. Flashner, Y.; Fisher, M.; Tidhar, A.; Mechaly, A.; Gur, D.; Halperin, G.; Zahavy, E.; Mamroud, E.; Cohen, S. The search for early markers of plague: Evidence for accumulation of soluble Yersinia pestis LcrV in bubonic and pneumonic mouse models of disease. FEMS Immunol. Med. Microbiol. 2010, 59, 197-206. [CrossRef]

40. Gode-Potratz, C.J.; Chodur, D.M.; McCarter, L.L. Calcium and iron regulate swarming and type III secretion in Vibrio parahaemolyticus. J. Bacteriol. 2010, 192, 6025-6038. [CrossRef] 
41. Bhavsar, S.M.; Dingle, T.C.; Hamula, C.L. The impact of blood culture identification by MALDI-TOF MS on the antimicrobial management of pediatric patients. Diagn. Microbiol. Infect. Dis. 2018, 92, 220-225. [CrossRef] [PubMed]

42. Osthoff, M.; Gürtler, N.; Bassetti, S.; Balestra, G.; Marsch, S.; Pargger, H.; Weisser, M.; Egli, A. Impact of MALDI-TOF-MS-based identification directly from positive blood cultures on patient management: A controlled clinical trial. Clin. Microbiol. Infect. 2017, 23, 78-85. [CrossRef] [PubMed]

43. CDC Web Site. Available online: https://www.cdc.gov/plague/healthcare/clinicians.html (accessed on 10 February 2022).

44. Joshi, K.; Thakur, J.; Kumar, R.; Singh, A.; Ray, P.; Jain, S.; Varma, S. Epidemiological features of pneumonic plague outbreak in Himachal Pradesh, India. Trans. R. Soc. Trop. Med. Hyg. 2009, 103, 455-460. [CrossRef]

45. Zahavy, E.; Heleg-Shabtai, V.; Zafrani, Y.; Marciano, D.; Yitzhaki, S. Application of fluorescent nanocrystals (q-dots) for the detection of pathogenic bacteria by flow-cytometry. J. Fluoresc. 2010, 20, 389-399. [CrossRef]

46. Levy, Y.; Flashner, Y.; Zauberman, A.; Tidhar, A.; Aftalion, M.; Lazar, S.; Gur, D.; Cohen, S.; Shafferman, A.; Mamroud, E. Protection against Plague Afforded by Treatment with Polyclonal $\alpha$ LcrV and $\alpha F 1$ Antibodies; Springer: Dordrecht, The Netherlands, 2010; pp. 269-274. 